\title{
Teleconsulta odontológica en tiempo del COVID-19. Revisión literaria
}

\author{
Dental teleconsultation in COVID-19 time. Literature review
}

\author{
Carmen Li-Pereyra $^{1 \mathrm{a}} ;$ Fernanda Ahumada-Rafael $^{1 \mathrm{~b}}$, Aldair López-Málaga $^{1 \mathrm{~b}}$, Pamela Alomia-Huamán $^{1 \mathrm{~b}}$, Ximena Rodríguez-De La \\ Torre Ugarte $^{1 \mathrm{~b}}$, Cindy Hernández-Beltrán ${ }^{2}$; Liliana Llacza-Arellano ${ }^{1 \mathrm{~b}}$, Rocio Zárate-Chavarría ${ }^{1 \mathrm{~b}}$
}

\section{RESUMEN}

La alta transmisibilidad del agente etiológico SARS-CoV-2, llevo al odontólogo a ser el profesional de la salud en presentar mayor riesgo de contagio debido a la consulta presencial donde se encuentra en contacto con saliva y sangre además del uso de aerosoles. Esto ha llevado al uso de la tecnología y telecomunicaciones como herramienta para una consulta no presencial, siendo conocida como Teleodontología. MÉTODOS: Los criterios de búsqueda para artículos científicos en formato electrónico han sido basados en tiempo de publicación, presencia de DOI, no se excluye ningún idioma; obtenidos de fuentes como PubMed, SciElo, Google Académico. Realizando la búsqueda en julio 2020. DESARROLLO: En el Perú, el $70 \%$ de contagios en odontólogos fue durante la consulta presencial, el aspecto legal y ético lleva a la desconfianza de efectuar una teleconsulta. El presente trabajo de investigación brinda recomendaciones desde el motivo de consulta, consentimiento informado, prescripción, seguimiento al paciente además del enfoque de la teleeducación. CONCLUSIONES: La teleodontología es una de las primeras opciones para brindar consulta en casos que no requieran una consulta presencial, sin embargo, la falta de un protocolo, leyes que lo avalen y adiestramiento ha llevado a generar desconfianza en efectuarla.

Palabras claves: Teleodontología; Coronavirus; Odontología. (Fuente: DeCS BIREME)

\section{Abstract}

The high transmissibility of the etiological agent SARS-CoV-2, led the dentist to be the health professional with the highest risk of contagion due to the face-to-face consultation where he is in contact with saliva and blood in addition to the use of aerosols. This has led to the use of technology and telecommunications as a tool for a remote consultation, being known as Teleodontology. The search criteria for scientific articles in electronic format have been based on publication time, presence of DOI, no language is excluded; obtained from sources such as PubMed, SciElo, Google Scholar. Carrying out the search in July 2020. In Peru, 70\% of infections in dentists were during the face-to-face consultation, the legal and ethical aspect leads to distrust of carrying out a teleconsultation. This research work provides recommendations from the reason for consultation, informed consent, prescription, patient follow-up, as well as the teleeducation approach. CONCLUSIONS: Teleodontology is one of the first options to provide consultation in cases that do not require a face-to-face consultation, however, the lack of a protocol, supporting laws and training has led to distrust in carrying it out.

KEY WORD: Teledentistry; Odontology; Coronavirus. (Source: MeSH NLM)

${ }^{1}$ Universidad de San Martín de Porres. Lima, Perú.

a Doctor en Odontología, Coordinadora de Internado Estomatológico

Estudiantes de pregrado

Correspondencia:

María Fernanda Ahumada

Correo electrónico: fer.ahumadarf@gmail.com

Dirección: Av. San Luis 1250, San Luis. Lima, Perú

Teléfono 5113464762
Este es un artículo Open Access distribuido bajo la licencia Creative Commons Atribución-No Comercial- Compartir Igual 4.0

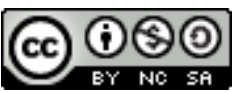

Citar como: Li-Pereyra C, Ahumada-Rafael F, López-Málaga A, Alomia-Huamán P, Rodríguez-De La Torre Ugarte X, HernándezBeltrán. C, Llacza-Arellano L, Zárate-Chavarría R. Teleconsulta odontológica en tiempo del COVID-19. Revision literaria. KIRU. 2020; 17(4): 237-245. https://doi.org/10.24265/kiru.2020.v17n4.9 


\section{INTRODUCCION}

La nueva neumonía causada por coronavirus (NNC) ha tenido una rápida expansión desde el primer caso reportado de un ciudadano chino del poblado de Wuhan hasta llegar a presentar nuevos casos en provincias aledañas y posteriormente otros 24 países. La alta transmisibilidad del agente etiológico, SARSCoV-2 llevó a la Organización Mundial de la Salud (OMS) el día 30 de enero del presente año a declarar una emergencia de salud pública de dimensiones internacionales, siendo el último reporte del día 04 de septiembre 2020 presentando $26,493,914$ casos confirmados y 872.390 muertes a nivel global ${ }^{(1-9)}$.

A inicios del mes de marzo, se reportó el primer caso de infección por SARS-CoV-2 en el Perú, llevando a las autoridades a declarar emergencia sanitaria nacional luego de que la OMS declare la NNC como pandemia mundial $(5,10)$

Debido a que la transmisión de este virus es mediante el contacto con pacientes infectados, los profesionales de la salud bucal, que se encuentran más expuestos debido a que en la consulta o atención existe la exposición a saliva y sangre sin mencionar la utilización de aerosol en las piezas de mano de alta velocidad, jeringa de aire y agua así como el ultrasonido; produciéndose un alto riesgo de contagio en la práctica clínica llevando a tener que presentar un cambio en el protocolo de atención. La propuesta de una atención a través de la tecnología ya había sido mencionada y aplicada con anterioridad, para consulta a distancia con los profesionales de la salud y pacientes que se encuentren en zonas rurales, llamándola teleodontología (TD) ${ }^{(1-3,5,11-17)}$.

La TD se basa en el intercambio de información incluyendo imágenes y/o videos para lograr brindar una consulta a larga distancia a través de la tecnología cubriendo los aspectos de una teleeducación y teleasistencia, siendo promovido por la Asociación Dental Americana mientras se hace frente a la pandemia por el nuevo coronavirus ${ }^{(12,14,17-21) \text {. }}$

\section{PROCESO DE SELECCIÓN DE ARTICULOS}

Para el presente artículo de revisión se consultaron 36 artículos en formato electrónico incluyendo trabajos de investigación publicados en la modalidad de cartas al editor, procedentes de diferentes fuentes de búsqueda como PubMed, SciELO, Google Académico, sin excepción de idioma tales como español, inglés y portugués Se procedió a una selección de artículos utilizando criterios como el tiempo de publicación, el cual debía ser no mayor a 5 años de antigüedad exceptuando artículos que presentaban información indispensable para el presente trabajo, se descartaron los artículos que no presentaban un identificador de objeto digital (DOI), teniendo un resultado de 21 artículos seleccionados en julio 2020. Adicionalmente, se consultó guías, protocolos y datos estadísticos de diferentes entidades tales como; Organización Mundial de la Salud, Colegio Odontológico del Perú, Orden Nacional de Cirujanos Dentistas de Francia, Fiscalía del Colegio de Cirujanos Dentistas de Costa Rica y Asociación Latinoamericana de Odontopediatría; datos estadísticos obtenidos de la página web de la Universidad de Medicina Johns Hopkins; y la Resolución Ministerial 1172020/MINSA procedente de Perú.

Las palabras claves para la búsqueda realizada fueron:"coronavirus", "teledentristy", "teleodontology", "odontology".

\section{REVISIÓN DE LA LITERATURA}

La teleodontología, actualmente es la primera opción de atención a pacientes frente a la crisis de salud pública, es la rama de la profesión odontológica donde la atención al paciente es brindada mediante el intercambio de información entre el paciente y el odontólogo tratante a través del uso de la tecnología, siendo esta por videoconferencia, redes sociales, correo electrónico, incluyendo imágenes y/o videos de ambas partes. Esta rama de la odontología cubre los aspectos de teleasistencia y teleeducación, siendo útil para la mayoría de las especialidades que no requieren atención presencial de urgencia $^{(12-17,21)}$.

Se ha definido dos formas de llevar a cabo una Teleconsulta, la primera es la sincrónica siendo definida como la consulta llevada en tiempo real por videoconferencia y/o llamada telefónica; la segunda es la asincrónica, definida cuando se tiene un tiempo de espera entre la consulta del paciente y la respuesta del profesional, usualmente utilizando redes sociales tales como la aplicación WhatsApp, plataformas de videoconferencias, inclusive el uso de un software disponible en el mercado local como por ejemplo doctocliq.com; siendo la combinación de ambos la teleconsulta mixta, debido al tiempo de seguimiento (mediano o largo plazo) ${ }^{(15,21-24)}$. 
Las siguientes consideraciones son planteadas para una atención dental que no requiera atención de forma presencial de urgencia y/o emergencia; se encuentra basado en la "Guía para el manejo telefónico de una solicitud de atención dental urgente en el contexto de la etapa 3 de la epidemia de COVID-19" de la Orden Nacional de Cirujanos Dentistas de Francia; el protocolo brindado por la Asociación Latinoamericana de Odontopediatría y el "Protocolo Teleconsulta Dental" de la Fiscalía del Colegio de Cirujanos Dentistas de Costa Rica ${ }^{(25-27)}$.

1) Consideraciones para la Teleconsulta en odontología ${ }^{(25-27)}$

2) Se recomienda establecer un orden para efectuar la Teleconsulta.

a) Pre-consulta Virtual: Primer contacto del paciente con el consultorio dental, específicamente con la asistente $\mathrm{O}$ secretaria del odontólogo.

i) Se enviará un primer documento que consiste en el formato de datos generales incluyendo preguntas de tamizaje para detección de NNC, que deberá ser reenviado con todos los datos solicitantes.

ii) Se evaluará el motivo de consulta, si se considera pertinente se comunicará si es posible llevar a cabo una teleconsulta 0 si se tendría que realizar una consulta de manera presencial.

iii) Confirmada la Teleconsulta se le enviará un segundo documento que consiste en el consentimiento informado sobre la teleconsulta.

Se recomienda al odontólogo no efectuar la teleconsulta en el caso que el paciente no reenvié los documentos completamente $y$ correctamente llenados.

b) Consulta Virtual: La consulta como tal puede ser llevada de manera asincrónica, llevada mediante un intercambio de información con un tiempo de espera para la respuesta del odontólogo; así como sincrónica, consulta en tiempo real mediante una llamada telefónica o videoconferencia. Considerando los posibles escenarios de accidentes dentales que se puede manejar mediante teleconsulta, el paciente deberá seguir cada indicación del profesional de manera correcta.
Durante la teleconsulta se efectúa el llenado de historia clínica, verificación del consentimiento informado lo cual formará parte de la carpeta digitalizada del paciente junto al formato de datos generales enviado previo ${ }^{(15,21,25-27) \text {. }}$

i) Dolor dental: El paciente debe informar la duración y lugar específico donde se presenta el dolor, si es posible fotos intraorales como extraorales, indicar la aparición del dolor, si es espontáneo o provocado (cambio de temperatura, durante la masticación, al acostarse), el tipo de dolor si es persistente, intermitente, pulsante y radiante. Para indicar la intensidad del dolor, se recomienda al odontólogo la utilización de una Escala Numérica, basado en niveles del dolor enumerados del 1 al 10; el número 0 expresa ausencia del dolor mientras que el 10 expresa la mayor intensidad ${ }^{(25,26,28)}$.

ii) Infección bucal: El paciente debe indicar si presenta hinchazón, explicando si es intra o extraoral (se debe especificar la zona), cambio en la piel (eritema, calor, crepitación a la palpación, presencia de fístula). Además de indicar la duración de la infección, así como la presencia de movilidad dental en la parte afectada. Para tratar una infección por Teleconsulta se recomienda que sea de forma sincrónica, mediante una videoconferencia ${ }^{(25,26)}$.

iii) Traumatología: En este aspecto, es una búsqueda clínica más exhaustiva, se busca signos de trauma en la cabeza (pérdida de conciencia, confusión, pérdida de equilibrio, dolor de cabeza, náuseas y vómitos), signos de fractura del maxilar/mandibular (alteración en la visión, molestias durante la masticación, deformación facial, epistaxis, desviación en el momento de apertura y/o cierre) y signos asociados con el trauma del tejido blando (heridas abiertas). Si el traumatismo conlleva una expulsión o fractura dental, se debe indicar si ha perdido la totalidad o solo la parte coronal de la pieza dental, esto llevaría a una señal de 
exposición pulpar pidiéndole al paciente si puede presenciar un punto rojo hacia el centro de la pieza dental; si se presenta un signo de dislocación, indicar si existe presencia de movilidad dental y si es capaz de realizar movimiento de cierre mandibular. Para tratar un traumatismo dental se recomienda realizar la Teleconsulta de forma sincrónica, mediante una videoconferencia $^{(25,26)}$.

iv) Hemorragia: Es primordial saber si el paciente toma anticoagulantes y/o antiplaquetarios. Indicar el momento en el cual comenzó el sangrado, dando a conocer si fue provocado o espontáneo, así como la cantidad de sangre perdida y si la hemorragia se detuvo después de 15 minutos de compresión en la zona afectada $(25,2)$

v) Complicaciones post-exodoncia: EI paciente debe indicar si siguió las indicaciones y recomendaciones dadas por el odontólogo que realizó la exodoncia, así como el cumplimiento de la prescripción médica además brindar información sobre la exodoncia como hace cuánto tiempo se la realizó, el motivo por el cual fue realizada y si le realizaron suturas. También es importante que nos indique la presencia de dolor, detallando la semiología y la presencia de sangrado que no pueda ser controlado $(25,26)$.

vi) Gingivitis: El odontólogo debe preguntar si la zona afectada sangra con facilidad al momento del cepillado dentario, si hay presencia de zonas blanquecinas en la encía papilar, así como si presenta halitosis o siente sabor a sangre. Para estos casos es importante que el paciente brinde fotografías
intraorales

vii) Pericoronaritis: El odontólogo debe preguntarle al paciente si observa que la pieza está cubierta total o parcialmente por la encía, la presencia de halitosis además de distinguir un sabor amargo y si siente que el momento de masticar siente de muerde la encía de la zona afectada $^{(25,26)}$.

c) Prescripción: Después de la evaluación de los signos que indica el paciente, si hay necesidad de prescribir para el alivio de síntomas se debe tener en cuenta el peso, edad, alergias, tratamiento por alguna enfermedad sistémica ya existente. Se recomienda al odontólogo, el almacenamiento de la prescripción brindada al paciente en una carpeta digitalizada ${ }^{(25-27)}$.

d) Post-consulta: El odontólogo deberá comunicarse con el paciente después de las primeras 48 horas de iniciado el tratamiento a seguir, así como el paciente deberá comunicarse si la gravedad de los síntomas empeora para que el profesional realice una siguiente consulta, indicando nuevos medicamentos ${ }^{(26)}$.

\section{3) Teleeducación}

La teleodontología también presenta un aspecto de teleeducación, este puede ser aplicada para la odontología preventiva, enseñando por videoconferencia o enviando un video, los pasos para un correcto cepillado dental; así como también aplicando para la ortodoncia, en la enseñanza de un correcto cambio de ligas ortodónticas, limpieza de aparatos ortopédicos; en la especialidad de rehabilitación oral, se le puede brindar al paciente un tutorial mediante un video sobre el empleo de un adhesivo dental para colocar un provisional desprendido, así como un mantenimiento adecuado de la prótesis dental ${ }^{(20,21,29)}$.

\section{4) Aspecto ético y legal:}

La confidencialidad de la información que el paciente brinda al odontólogo, así como la adecuada forma de utilizar la prescripción, lleva a generar problemas legales como éticos, siendo causante de la poca fiabilidad que presentan los odontólogos con la teleodontología. El consentimiento informado es el único documento legal que se tendría para una teleconsulta, donde se le comunica al paciente que toda información que brinde está siendo guardada en una carpeta al igual de la grabación de la consulta mediante videoconferencia $^{(15,17,21)}$.

En el Perú, se cuenta con la Resolución Ministerial 117-2020/MINSA ${ }^{(30)}$ que establece "los criterios para la implementación y 
desarrollo de los servicios de Telemedicina síncrona y asíncrona en las Instituciones Prestadoras de Servicios de Salud", sin embargo, no cuenta con una ley sobre la Teleconsulta específicamente para odontología que hable de los derechos y deberes tanto del profesional como del paciente así mismo tampoco existe una ley sobre la prescripción farmacológica mediante teleconsulta ${ }^{(30)}$.

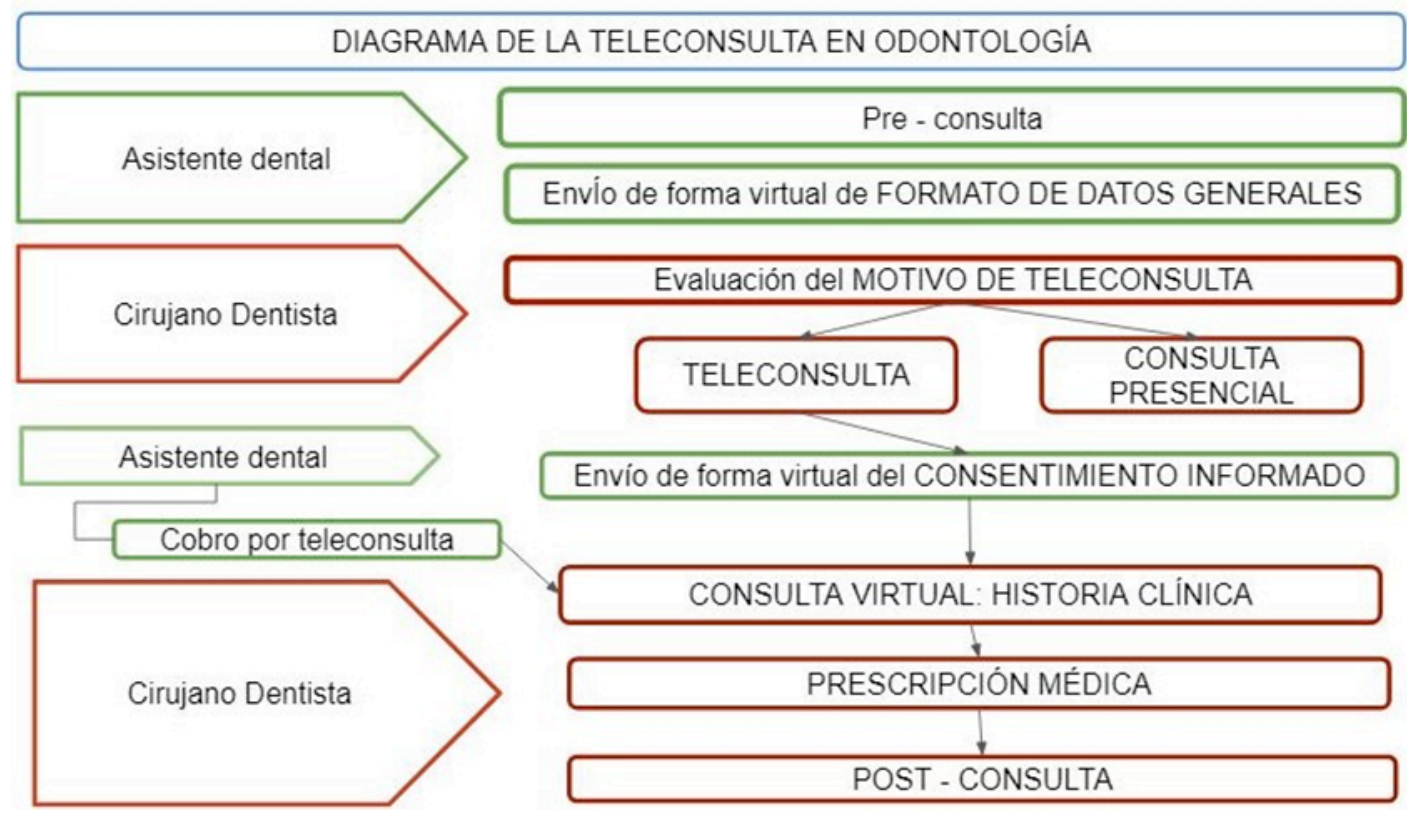

Figura.1. Diagrama de la Teleconsulta en Odontología

Fuente: Trabajo propio

\section{DISCUSION}

La teleodontología no es una nueva rama de la odontología, fue Cooks quien la definió por primera vez en el año 1997 como "la práctica de usar tecnologías de videoconferencia para diagnosticar y proporcionar consejos sobre el tratamiento a distancia" sin embargo la aplicación de la teleodontología, fue en el año 1994 en el proyecto militar "Proyecto de Acceso Dental Total del Ejército de los Estados Unidos", teniendo como objetivo mejorar la atención al paciente así como la educación dental además de una mejor comunicación entre el odontólogo y los laboratorios dentales; el éxito del proyecto demostró que se logro extender la asistencia dental a lugares remotos y rurales además de observarse una reducción en el costo de atención. Durante los años siguientes se llevaron a cabo proyectos para evaluar el uso de la teleodontología, siendo los países de Taiwán, Irlanda, Estados Unidos y Brasil los que indicaron que la teleodontología es aplicable y fiable ${ }^{(13,17,31) \text {. }}$

Petruzzi y De Beneditis, realizaron un estudio sobre el uso de la aplicación WhatsApp en el diagnostico presuntivo de lesiones de la cavidad oral comparándolo con un diagnóstico clínico-patológico; presentando un resultado de "una tasa de concordancia del 82\%" entre ambos diagnósticos; logrando facilitar una atención y diagnóstico temprano a pacientes que residían en zonas rurales además de la reducción de costos de transporte para los pacientes y el tiempo de espera para ser atendidos. Carrad et al. publicaron su experiencia en la teleodontología, con su servicio Estomato.Net realizado por el Ministerio de Salud de Brasil; siendo descrito como "una plataforma basada en la nube que almacena información relacionada con cada caso" permitiendo una auditoria y mejor organización, inclusive la creación del protocolo para el servicio y 
brindando "un tutorial de grabación de fotografías para los solicitantes que utilizan el servicio" obteniendo como resultado la aprobación del $90 \%$ de los solicitantes ${ }^{(16,32)}$.

En la actualidad, los momentos críticos de la salud pública han llevado a los profesionales de la salud a aplicar la teleconsulta, sin embargo, el principal problema que puede encontrarse es el aspecto económico y legal; sin mencionar que la calidad de las fotografías enviadas por los pacientes puede ser un factor negativo en el momento de diagnosticar a pesar de la distancia $(15,17,18,21)$.
El Colegio Odontológico del Perú (COP) el día 1 de julio 2020 informó mediante el "Comando Covid del COP" y Fondo de Prevención Social (fps), un registro epidemiológico indicando que el $70 \%$ de los contagios a odontólogos se produjo durante la consulta presencial, teniendo hasta el momento del informe un total de 158 contagiados, 18 odontólogos hospitalizados, 07 en la Unidad de Cuidados Intensivos y 18 fallecidos, sin mencionar el número de casos sospechosos que ascienden a 480 (33) (Figura 2).

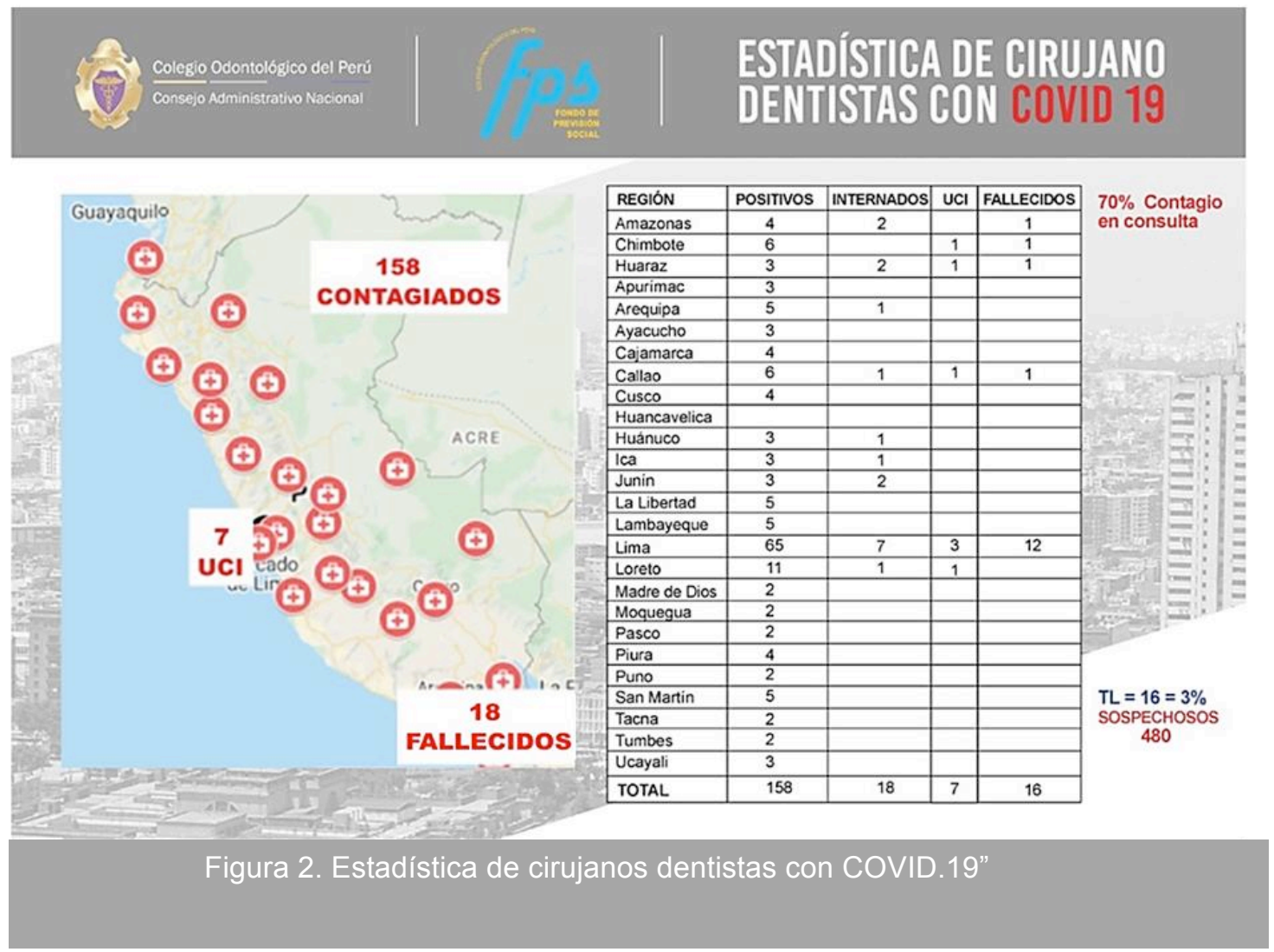

En el Perú, la rama de teleodontología no es fiable desde el punto de vista profesional debido a que no existe un entrenamiento previo, así como la falta de un sistema nacional de teleodontología, sin mencionar la falta de un protocolo a nivel nacional y la falta de leyes que lo avalan $(12,17,29)$

La teleodontología en el Perú puede ser de gran utilidad mediante el punto de vista asistencial, educativo e investigación, los odontólogos serumistas pueden utilizarla para el intercambio de información entre colegas debido a la distancia remota, así como el seguimiento a pacientes que no requieren necesidad de asistir de forma presencial a la consulta. Debido a la pandemia del NNC, los odontólogos están conociendo las aplicaciones de la teleodontología inclusive llevándola a cabo sin un protocolo definido, teniendo dificultades al momento de realizar una teleconsulta ${ }^{(18,19,21)}$. 


\section{CONCLUSIONES}

La pandemia por el SAR-CoV-2 ha llevado al odontólogo a ser uno de los profesionales de la salud en presentar mayor riesgo de contagio del virus, debido a la consulta presencial donde están en contacto con saliva y sangre sin mencionar el uso de aerosoles. Esto ha llevado a impulsar la modernización, innovación y aprovechamiento de la tecnología; con el fin de salvaguardar la salud del odontólogo, mediando la realización de una teleconsulta.

El presente artículo recomienda la implementación de la teleodontología además de exponer consideraciones para una mejor aplicación. Recomendando, no realizar la teleconsulta si el paciente no envía el cuestionario de salud, se sugiere incluir preguntas de tamizaje por el SARS-CoV-2; consentimiento informado, sugiriendo comunicar la grabación de la teleconsulta además de almacenamiento de toda información brindada por el paciente, así como la prescripción. Se recomienda al odontólogo, la digitalización de la información brindada como formato general de datos, consentimiento informado, historia clínica, grabación de la teleconsulta, prescripción médica y todo intercambio de información en una carpeta digitalizada que será guardada el tiempo que establece las normas vigentes del Perú.

En el Perú, la falta de un sistema nacional para la teleodontología incluyendo un protocolo general para la aplicación de la teleconsulta en odontología, así como leyes que avalen inclusive la prescripción del odontólogo en una teleconsulta, dificulta poseer la confianza de efectuar.

Sin mencionar la falta de entrenamiento en las universidades, los egresados de diferentes facultades de odontología no han sido adiestrados ni presentan conocimiento alguno sobre cómo llevar a cabo una teleconsulta, llevando esta falta de conocimiento a la poca promoción que presenta la teleodontología, debido a esta realidad el presente trabajo de investigación no solo expone consideraciones para una teleconsulta durante la pandemia del SARS-CoV-2 también propone a las entidades autorizadas a la promoción, promulgación de leyes, protocolo establecido además de la posible instauración de un programa de adiestramiento en teleconsulta para el odontólogo colegiado y la incrementación en el plan de estudios de un curso de teleodontología en las diferentes universidades.

Contribución de autoría: CLP, FAR, ALM, $\mathrm{PAH}, \quad \mathrm{XRDLTU}, \mathrm{CHB}$ participaron en la recolección y análisis de datos, redacción y aprobación de la versión final del manuscrito. LLLA, RZCH participaron en la recolección de datos.

Fuentes de financiamiento: autofinanciada.

Conflicto de Interés: Los autores declaran no tener conflicto de interés.

\section{REFERENCIAS}

1. Suárez Salgado $S$, Campuzano R, Dona Vidale M, Garrido Cisneros E, GiménezMiniellot. Recomendaciones para prevención y control de infecciones por SARS-CoV-2 en odontología. Revista Odontología [Internet]. 2020 [citado 13 julio 2020]; 22(2): 5-32. Disponible en: http://revistadigital.uce.edu.ec/index.php/od ontologia/article/view/2211

2. Ramírez-Velásquez $\mathrm{M}$, Medina-Sotomayor $\mathrm{P}$, Morocho Macas Ángel. Enfermedad por coronavirus 2019 (COVID-19) y su repercusión en la consulta odontológica: una revisión. OS [Internet]. 2020 [citado 13 julio 2020]; 23 (2): 139-146. Disponible en: https://revistasinvestigacion.unmsm.edu.pe /index.php/odont/article/view/17758

3. Peng X, Xu X, Li Y, Cheng L, Zhou, Ren B. Transmission routes of 2019-nCoV and controls in dental practice. Int $\mathrm{J}$ Oral Sci OS [Internet]. 2020 [citado 13 julio 2020]; 12: e9. Disponible en: https://doi.org/10.1038/s41368-020-0075-9

4. Georgakopoulou E. Telemedicina asistida digitalmente durante la pandemia del SARS-CoV-2 para detectar emergencias de medicina oral. Oral Diseases. [Internet]. 2020 [citado 13 julio 2020] Disponible en: https://doi.org/10.1111/odi.13383

5. Pereira L.J, Pereira-Cassio V, Murata Ramiro M, Pardi V, Pereira-Dourado S.M. Biological and social aspecto of Coronavirus Disease 2019 (COVID-19) related to oral health. Braz.oral res. [Internet] 2020 [citado 13 julio 2020];34: e041.Disponible

https://doi.org/10.1590/1807-3107bor2020.vol34.0041

6. Martínez-Camus D.C, Yévenes-Huaiquinao S.R, Dental Care During COVID-19 Pandemic. Int. J. Odontostomat [Internet]. 2020. [citado 15 julio 2020]; 14(3): 288-295. Disponible

en: https://scielo.conicyt.cl/scielo.php?script=sc i_arttext\&pid=S0718$381 \times 2020000300288 \&$ Ing $=$ en 
7. Singhai T, A Review Coronavirus Diseases2019 (COVID-19). Indian J Pediatr. [Internet] 2020 [citado 15 julio 2020]; 87(4): 281-6 Disponible en https://doi.org/10.1007/s12098-020-03263$\underline{6}$

8. Organización Mundial de la Salud. [Internet] Suiza: OMS; 2020 [actualizado 30 julio 2020; citado 13 julio 2020]. Cronología de la respuesta de la OMS a la COVID-19. Disponible en: https://www.who.int/es/newsroom/detail/29-06-2020-covidtimeline

9. Jhons Hopkins University [Internet]. Estados Unidos: Coronavirus Resource Center; 2020 [ actualizado 6 septiembre 2020; citado 4 septiembre 2020]. Global Map. Disponible en: https://coronavirus.jhu.edu/map.html

10. Márquez Velásquez JR. Teleconsulta en la pandemia por Coronavirus: desafíos para la telemedicina pos-COVID-19. Rev Colomb Gastroenterol [Internet] 2020 [citado 13 julio 2020]; 35 Supl 1: 5-16. Disponible en: https://revistagastrocol.com/index.php/rcg/a rticle/view/543

11. Gaitán LA, Leyva-Huerta ER, CruzGonzales R, Carmona RD, Rodríguez ME, Gómez AA. COVID-19 y el cirujano dentista. Una revisión integral. Rev Odont Mex. [Internet] 2019 [citado13 julio 2020]; 23(4): 207-215. Disponible en: https://www.medigraphic.com/cgibin/new/re sumen.cgi?IDARTICULO=93178

12. Ghai S. Teledentristy during COVID-19 pandemic. Diabetes Metah Syndr [Internet] 2020 [citado 13 julio 2020]; 14 (5): 933-5. Disponible en: https://doi.org/10.1016/j.dsx.2020.06.029

13. Alves da Mota Santana L, Lima dos Santos MA, Melo de Albuquerque HI, Ferreira dos Santos Costa S, Rezende-Silva E, Gercina AC, Mitsunari Takeshita W. Teledentistry in Brasil: a viable alternative during COVID-19 pandemic [Internet] 2020 [citado 13 julio 2020]; 23: e200082. Disponible en: https://doi.org/10.1590/1980549720200082

14. Telles-Araujo G, Araujo, García Caminha $R$, Samaan Kallás $M$, da Silva Santos $P$. Teledentistry support in COVID-19 oral care. [Internet] 2020 [citado 13 julio 2020]; 75: e2030. Disponible en: https://doi.org/10.6061/clinics/2020/e2030

15. De Almeida Geraldino R, Vicente Melo de Lucas Rezende L, Queiroz da-Silva C, Franco Almeida J. Remote diagnosis of traumatic dental injuries using digital photographs captured via a mobile phone. Dent Traumatol [Internet] 2017 [citado 13 julio 2020]; 33 (5): 350-7. Disponible en: https://doi.org/10.1111/edt.12347

16. Carrad VC, Roxo Gonçalves M, Rodríguez Strey J, Pilz C, Martins MAT, Martins M.D, Schmitz CA et al. Telediagnosis of oral lesions in primary care: the EstomatoNet Program. Oral Diseases [Internet] 2018 [citado 13 julio 2020]; 24 (6): 1012-9. Disponible https://doi.org/10.1111/odi.12851

17. Jampani ND, Nutalapati $R$, Dontula B, Bovapati R. Aplications of Teledentristy : A literature review and update. J Int Soc Prevent Community Dent [Internet] 2011 [citado 13 julio 2020]; 1 (2): 37-44. Disponible en: http://www.jispcd.org/text.asp?2011/1/2/37/ 97695

18. Böhm da Costa C, da Silva Peralta F, Schaefer Ferreira de Mello AL. How has Teledentristy been applied in Public Dental Health Servicies?An Integrative Review. Telemedicine and e-Health [Internet] 2019 [citado 13 julio 2020]; 26(7): 945-954. Disponible https://doi.org/10.1089/tmj.2019.0122v

19. Silva AS, Rizzante FA, Picolini M, Campos K, Correa C, Franco EC et al. Bauru School of Dentistry Tele-Health League: an educational strategy applied to research, teaching and extension among applications in tele-health. J Appl Oral Sci. [Internet] 2011 [citado 13 julio 2020]; 19(6): 599-603. Disponible https://www.ncbi.nlm.nih.gov/pmc/articles/P MC3973460

20. Saccomanno S, Quinzi V, Sarhan S, Laganá D, Marzo G. Perspective of teleorthodontics in the COVID-19 emergency and as a future tool in daily practice. Eur $\mathrm{J}$ Paediatr Dent [Internet] 2020 [citado 13 julio 2020]; 21(2): 157-162. Disponible en: https://pesquisa.bvsalud.org/globalliterature-on-novel-coronavirus-2019ncov/resource/en/covidwho-612267

21. Cartes-Velásquez $R, \quad$ Bustos-Leal $A$. Teleodontología: Conceptos, experiencias y proyecciones. Odontoestomatología [Internet] 2012 [citado 13 julio 2020]; 14(20): 17-25. Disponible en: http://www.scielo.edu.uy/scielo.php?script=sci_ arttext\&pid=S168893392012000200003\&Ing=es

22. Machado RA, de Souza NL, Oliveira RM, Martelli Júnior $H$, Rogério Bonan PRF. Social media and telemedicine for oral diagnosis and counselling int the COVID-19 era. Oncol Oral [Internet] 2020 [citado 13 jul 2020]; 105: e104685. Disponible en https://doi.org/10.1016/j.oraloncology.2020.104 685

23. Doctocliq. [Internet] Perú: Doctocliq.com [citado 15 jul 2020] Disponible en: http://www.doctocliq.com/

24. Chaple-Gil AM, Afrashtehfar KI. Telegram Messenger: A suitable tool for Teledentistry. J Oral Res [Internet] 2020 [citado 14 jul 2020]; 9 (1): 4-6. Disponible en: https://doi.org/10.17126/joralres.2020.001 
25. Odhre National des Chirurgiens-Dentistes. Guide pour la prise en charge téléphonique d'une demande de soins dentaires urgents dans le cadre du stade 3 de l'épidémie de COVID-19. Francia: ADF; 2020. Disponible en: https://www.adf.asso.fr/media/59/download/Gu ide-prise-en-charge-telephonique-urgencesdentaires.pdf? $v=1$

26. Asociación Latinoamericana de Odontopediatría. Teleodontología: Aplicación a la Odontopediatría durante la pandemia COVID-19. Revista de Odontopediatría Latinoamericana [Internet] 2020 [citado 13 jul 2020]; 10(2): e3. Disponible en: https://www.adf.asso.fr/media/59/download/Gu ide-prise-en-charge-telephonique-urgencesdentaires.pdf? $v=1$

27. Fiscalía del Colegio de Cirujanos Dentistas de Costa Rica. Protocolo Teleconsulta Dental. [Internet] 2020 [citado 13 julio 2020] Disponible en: http://www.colegiodentistas.org/sitCol/wpcontent/uploads/2020/04/PROTOCOLOTELECONSULTA-DENTAL.pdf

28. Vicente-Herrera MT, Delgado-Bueno $S$, Bandrés-Moya F, Ramírez-Iñiguez-de-la-Torre MV, Capdevilla-García L. Pain assessment Comparative review of scales and questionnaires. Rev Soc Esp Dolor. [Internet] 2018 [citado 06 septiembre 2020]; 25 (4): 228$232 . \quad$ Disponible en: http://dx.doi.org/10.20986/resed.2018.3632/20 $\underline{17}$
29. Boringi M, Waghrav S, Lavanya R, Gandhi DB, Bandam RK, Harsha $\mathrm{N}$ et al. Knowledge and Awareness of Teledentistry among Dental Professionals-A Cross Sectional Study. J Clin Diagn Res. [Internet] 2015 [citado 13 julio 2020]; 9(8): ZC41-ZC44. Disponible en: https://pubmed.ncbi.nlm.nih.gov/26436045/

30. Directiva para la implementación y desarrollo de los servicios de telemedicina síncrona y asíncrona. Resolución Ministerial N¹172020/MINSA. El Peruano (27-03-2020) https://busquedas.elperuano.pe/normaslegales laprueban-la-directiva-administrativa-n-285minsa2020digte-resolucion-ministerial-no-1172020minsa-1865175-4/

31. Singhal T. A Review Coronavirus Diseases2019 (COVID-19). Indian J Pediatr. [Internet] 2020 [citado 15 julio 2020]; 87(4): 281-6. Disponible en: https://doi.org/10.1007/s12098020-03263-6

32. Petruzzi M, De Benedittis M. WhatsApp: A telemedicine platform for facilitating remote oral medicine consultation and improving clinical examinations. Oral Surg Med Oral Pathol Oral Radiol. [Internet] 2016 [citado 04 $\begin{array}{llll}\text { septiembre 2020]; } 121 & \text { (3): 248-254. }\end{array}$ Disponible en; https://doi.org/10.1016/j.00oo.2015.11.005

33. Colegio Odontológico del Perú; Registro Epidemiológico 01 Julio 2020. Disponible en: https://es-

la.facebook.com/photo. php?fbid $=26511218951$ 75847\&set=a.1404219566532759\&type $=3$ \&the ater

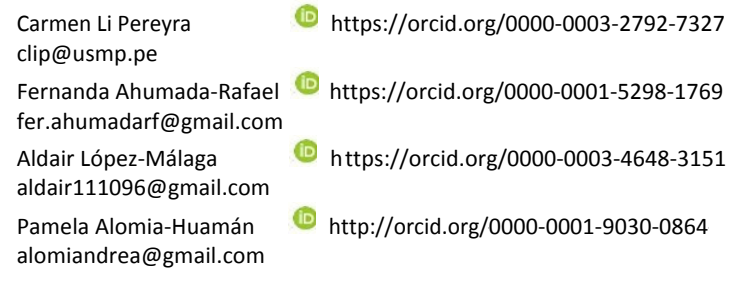
Ximena Rodríguez De La Torre Ugarte http://orcid.org/0000-0003-0520-9033
boster1408@gmail.com
$\begin{aligned} & \text { Cindy Hernández-Beltrán } \\ & \text { cindyhb6@gmail.com }\end{aligned}$
$\begin{aligned} & \text { Liliana Llacza-Arellano } \\ & \text { Liliana.Llacza2909@gmail.com }\end{aligned}$
$\begin{aligned} & \text { Rocio Zarate Chavarria } \\ & \text { rocysofi2420@gmail.com }\end{aligned}$ 